\title{
A Three Area Interconnected Power System Network Load Frequency Controller Simulator
}

\author{
Ibrahim O Muritala ${ }^{*}$, M.B Mu'azu², E. A Adedokun ${ }^{3}$ \\ ${ }^{1,2,3} \mathrm{Ahmadu}$ Bello University \\ drolawalemi@gmail.com*
}

\begin{abstract}
This paper presents a MATLAB simulator of a three area interconnected power system of Thermal-Gas-Hydro. Nonlinearities intrinsic in the interconnected power system of communication delay, Generation Rate Constraint and Generation Dead Band were measured. Bat Inspired Algorithm was exploited to select the favourable parameters of the Model Predictive Controller and the Super Conducting Magnetic Energy Storage. Model Predictive Controller was the subordinate controller employed to minimalize the Area Control Error, Super Conducting Magnetic Energy Storage was the energy buffer to balance the load demand and the power generated. Integral Time Absolute Error was the performance metrics employed to minimize the Area Control Error. Parametric dissimilarity was tested on the inter-connected power system to observe the efficacy of the controller. Step load perturbation of $1 \%$ was concurrently applied to the three-area inter-connected network, $1.5 \%$ was introduced to the thermal generating unit, $1 \%$ was introduced to the gas and hydro generating unit. $\pm 50 \%$ Value of the tie-line was introduced to examine its effect on the frequency deviation. The results performed better when compared with Model Predictive Controller joined with Super Conducting Magnetic Energy Storage against the Model Predictive Controller without Super Conducting Magnetic Energy Storage in relations to settling time, overshoot and undershoot.
\end{abstract}

Keywords: Nonlinearities, Area Control Error, Model Predictive Controller, Super Conducting Magnetic Energy Storage, Load Frequency Control.

\section{Introduction}

The control of generating power system is becoming more challenging owing to the evolution of new technologies which require a stable power supply [1]. Increase in growth leads to complication in the power system. A control engineer is saddled with the responsibility of minimizing the frequency deviation when unexpected load variations occur in the system. Load Frequency Control (LFC) deals with the stability of a power generating system when the load is applied to the system [2]. LFC consists of two controllers via Primary and Secondary Control. The primary control is the regulation of the turbine speed limiter which is the governor by a regulation constant, the subordinate control deals with the ACE which is the summation of the product of the bias frequency with change in frequency and tie-line power deviation [3]. The tie-line power shares the power of the system based on the load changes [4]. Trial and error approach has been deployed to select parameters of the subordinate controllers (PID, MPC) and energy compensator devices (SMES, CES). Metaheuristic algorithms have been deployed to LFC in selecting the best gains of the subordinate controller and energy compensator devices to achieve frequency stability in a system [5].

Several kinds of literature have proposed different optimization algorithm for determining the optimal gains of LFC/Automatic Generation Control (AGC) for single unit area system, two area power system inter-connected network, multi-unit area inter-connected network. [6] Investigates a two area thermal-hydro inter-connected network with nonlinearity features of communication delay, Generation Rate Constraint (GRC), Generation Dead Band (GDB) using a subordinate controller of Model Predictive Control (MPC) tuned with Bat Inspired Algorithm (BIA). [7] Proposes MPC with Super Conducting Magnetic Energy Storage (SMES) for a two area interconnected system using BIA to select the optimal gains. The grid frequency is improved with BIA optimal selected gains for a three area inter-connected network using MPC with SMES and considering nonlinearity features [2]. Particle Swarm Optimization Fuzzy Logic Controller (PSO LFC) is used to control a two area multi-unit inter-connected network in the work of [4]. [8] Shows

Muritala, I., Mu'azu, M., \& Adedokun, E. (2018). A Three Area Interconnected Power System Network Load Frequency Controller Simulator. Kinetik: Game Technology, Information System, Computer Network, Computing, Electronics, and Control, 3(4), 295-304. doi:http://dx.doi.org/10.22219/kinetik.v3i4.657 
how Cuckoo Search (CS) is used to optimize Proportional Integral Derivative (PID) Controller for two area thermal Combined Cycle Gas Turbine (CCGT) with GRC. Cuckoo Search (CS) algorithm technique is implemented in a three area inter-connected network with GRC to select the optimal gains of a Proportional Integral (PI) controller [9]. Low pass filter is connected to a PID controller in the work of [10], Imperialist Competitive Algorithm (ICA) is used to select the favourable gains of the PID controller to control a three area inter-connected network with GRC considered.

In [2] the PID subordinate controller is a static gain controller which is not good in handling the uncertainties (GRC, GDB, and communication delay) in power network system, as such the purpose of LFC becomes challenging in matching the load demand and power generated. The increase in load on a power generating system can damage the mechanical moving parts in a generating unit [3], while the reduction in load translates to more power generated which leads to power wastage. This wastage can be channelled to an energy compensator in order to charge the compensator, as the compensator can compensate when there are more loads on the power system network.

This research evaluates a three area inter-connected power system network of ThermalGas-Hydro (TGH) with Bat Inspired Algorithm (BIA). The power system network will compare the performance of MPC based BIA with and without Super Conducting Magnetic Energy Storage (SMES), Integral Time Square Error (ITSE) is the performance metric that was employed to minimize the cost function. Nonlinearity features of communication delay, Generation Rate Constraint (GRC) and Generation Dead Band (GDB) will be measured in the design. Parametric variation will be applied to the design to examine the effectiveness of the controller. Consequently, the main contribution of the proposed research work is:

1. To design a three area TGH inter-connected power network with MPC subordinate controller and energy compensator of SMES

2. Designing of an appropriate subordinate MPC controller in MATLAB/SIMULINK R2017a

3. Selecting favourable parameters of the SMES and MPC using BIA, parametric variation of the network to evaluate the efficacy of the controller

4. To develop a user-friendly simulator in MATLAB/SIMULINK R2017a for effortlessness analysis for investigators who are not accustomed to programming.

\section{Research Method}

The system under examination is a three-area equal power Thermal-Gas-Hydro interconnected network. Tie-line distributes the power in the area [11]. The SMES transfer function modelling in SIMULINK is shown in Figure 1. Figure 2 shows the system investigated in this work with an MPC. The system is modelled in MATLAB/SIMULINK environment.

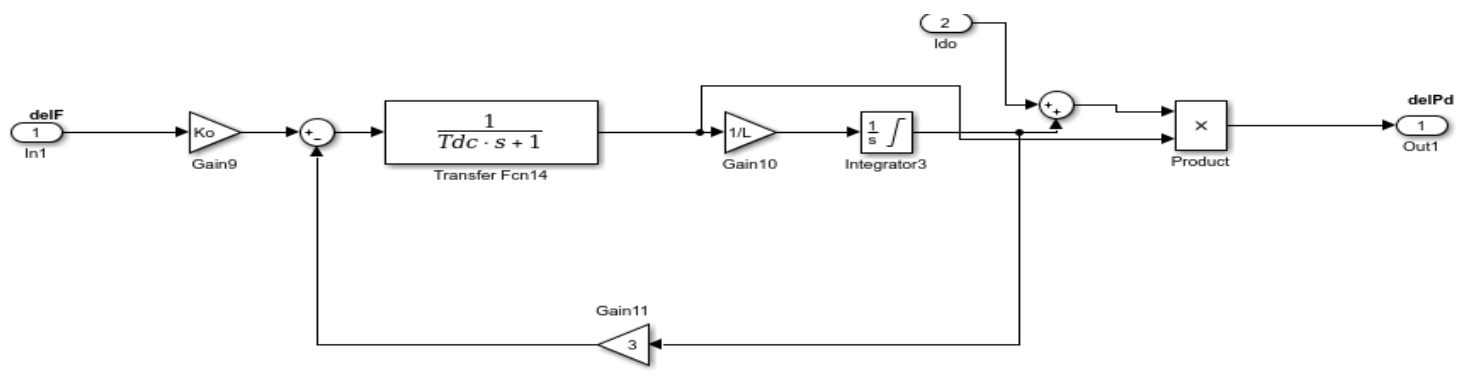

Figure 1. SMES Transfer Function

Figure 1 is the SMES transfer function block diagram. The SMES unit is a buffer that matches the load demand by the end user with the power generated by each unit [12]. The SMES charges when there is low demand and discharges when the consumer demands high load [2]. BIA is deployed to select the suitable parameters of the SMES.

BIA is a procedure proposed by [13] to solve optimization problems. Self-styled code which BIA uses in selecting favourable parameters is shown in Table 1.

Model predictive controller(MPC) predicts the output of the controller using the model of the system with minimally manipulated variable [14]. The MPC can be described by the prediction horizon, control horizon and cost function [14]. The prediction horizon $\left(N_{p}\right)$ is the number of samples in future the controller predicts the response of the plant with a minimal input, the control

KINETIK Vol. 3, No. 4, November 2018: 295-304 
horizon $\left(N_{c}\right)$ is number the of samples within the prediction horizon where the controller can effect the control action $N_{p} \geq N_{c}$. The cost function to minimize in the design of MPC is [14].

$$
J_{1}=\sum_{k=0}^{N_{p}}(\hat{y}-r)^{T} Q(\hat{y}-r)+\sum_{k=0}^{N_{c}} \Delta u^{T} R \Delta u
$$

Equation 1 is the cost function that provides minimal control effect.

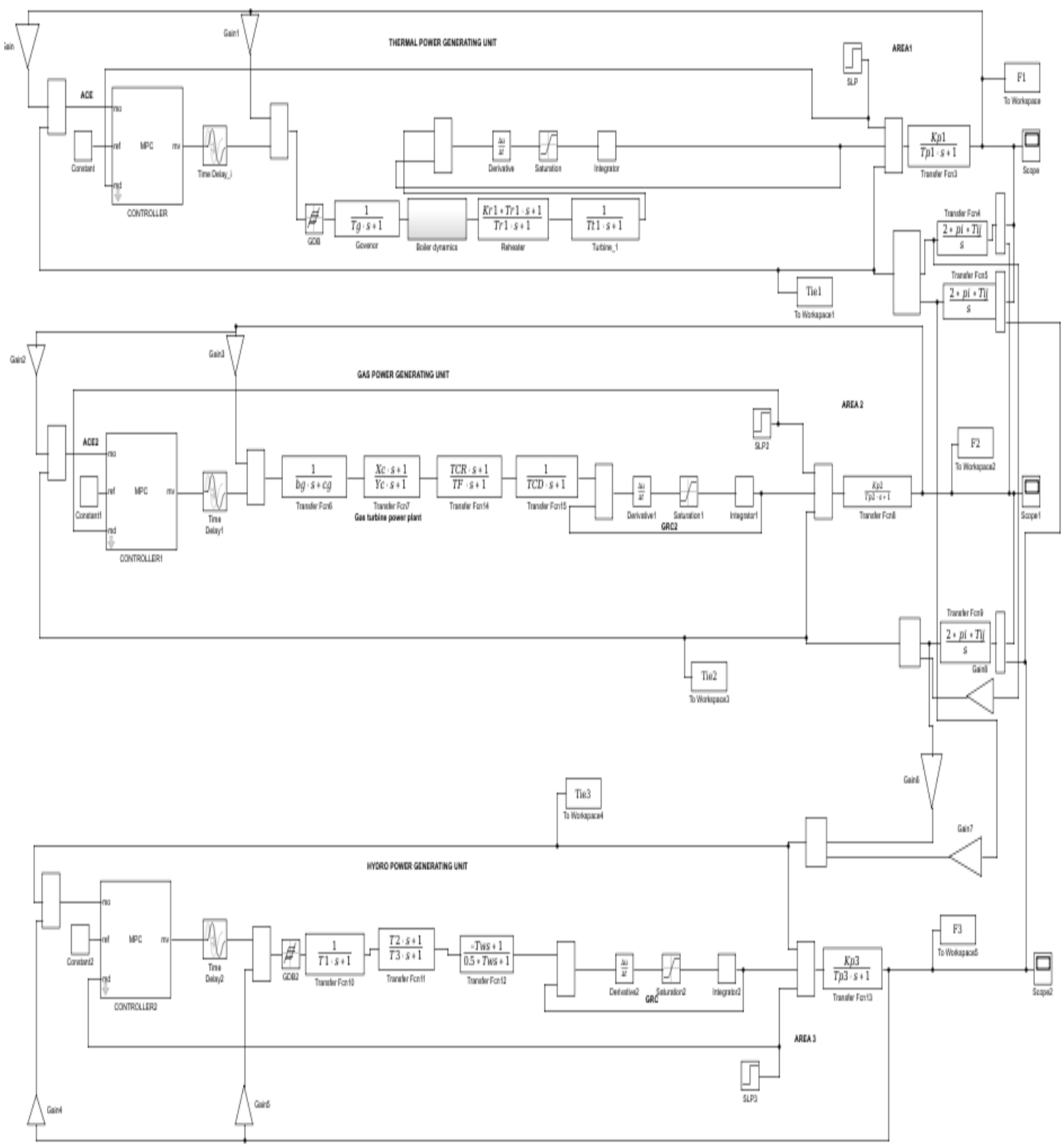

Figure 2. System Investigated

The MPC is depicted in Figure 3. The cost function for selecting the most favourable parameter of the controller is [2].

$$
J_{2}=I T S E=\sum_{n=1}^{3} \int_{0}^{\text {Simulated Time }} t *\left(A C E_{i}^{2}\right) d t
$$


Equation 2 is the Integral Time Square Error to be minimized by the inter-connected power network.

Table 1. Self-styled Code for BIA

$$
\text { Begin }
$$

0 Bats inhabitants are created with velocities $v_{i}$, positions $x_{i}$ and frequencies $f_{i}$ New results are generated If rand $(0,1)>$ pulse rate $\left(r_{i}\right)$, go to 1 otherwise 2

1 Pick-out a solution between the best results

A local result was attained by the bats around the nominated best result

2 Arbitrary Solutions were created by the bats If rand $(0,1)<$ loudness $\left(A_{i}\right) \&$, Present position $<$ global position goto 3 otherwise 4

3 Admit New results Intensify pulse rate and decrease loudness

4 The bats decide on the current best position Is iter<Maximum number of iterations? If true go to 0 , otherwise 5

5 Close

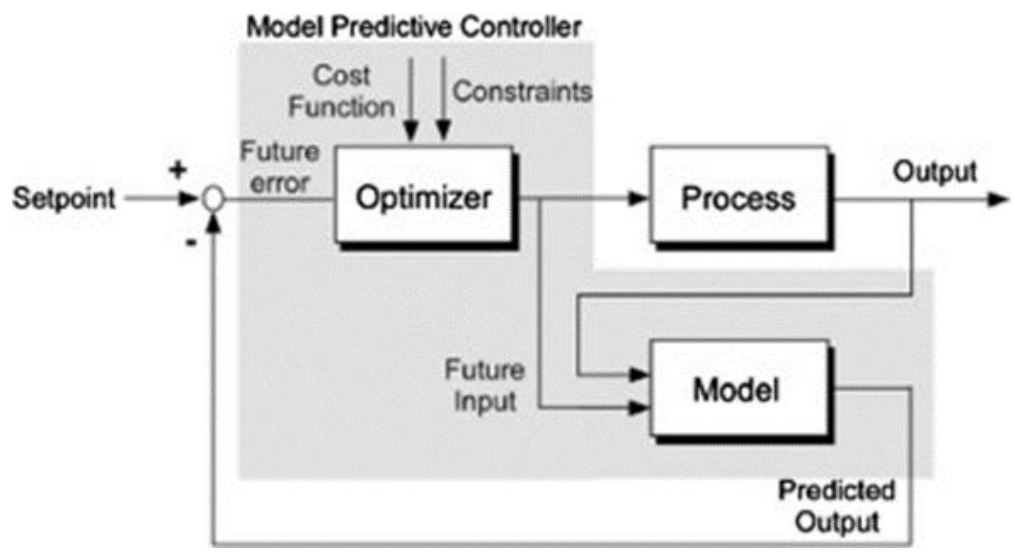

Figure 3. Model Predictive Controller General Framework

\section{Results and Discussion}

The work scrutinized the effects of MPC with SMES and Without SMES in this section of different parametric variations. The simulated result of different scenarios is discussed in this section. Figure 4 is the scenario of $1 \%$ concurrent disturbances on the three area network, the MPC with SMES frequency deviation is in the range of $\pm 0.05 \mathrm{~Hz}$, and the settling time is 20 seconds, while MPC without SMES is within the boundary of $\pm 0.15 \mathrm{~Hz}$, and the settling time is 40 seconds. In Figure 4 the load demand and the power generated balances in 20 seconds for the MPC with SMES, for MPC without SMES power generated matches load demand in 40 seconds. Figure 5 represents 1.5\% SLP for the thermal generating unit, 1\% SLP for the gas unit, and $1 \%$ SLP for the hydro unit. In Figure 5 the frequency deviation is within $\pm 0.05 \mathrm{~Hz}$ for each of the three areas, and the settling time is 20 seconds. The load demand and power demand ties in 20 seconds for the MPC with SMES, while for the MPC without SMES the frequency deviation is within $\pm 0.2 \mathrm{~Hz}$, and the settling time is 45 seconds. The load demand and power generated balances in 45 seconds for this scenario.

Figure 6 represents $50 \%$ increase tie-line variation, the frequency deviation is within $\pm 0.05 \mathrm{~Hz}$, while its frequency deviation is 20 seconds for the MPC with SMES, the MPC without SMES frequency deviation within $\pm 0.2 \mathrm{~Hz}$, and its settling time is 45 seconds.

Figure 7 represents $50 \%$ decrease tie-line variation, the MPC with SMES frequency deviation is within $\pm 0.05 \mathrm{~Hz}$, while its settling time is 20 seconds (the load demand and power generated is 20seconds). The MPC without SMES frequency deviation is within $\pm 0.15 \mathrm{~Hz}$, and its settling time is 40 seconds.

Figure 8 shows the MATLAB/GUI simulator developed for a three-area thermal-gas-hydro power inter-connected network. Table 2 shows the optimum gains for the MPC and SMES for the three area inter-connected power system.

KINETIK Vol. 3, No. 4, November 2018: 295-304 


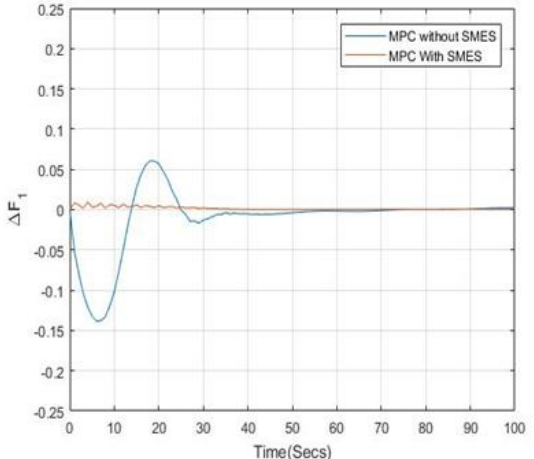

(a)

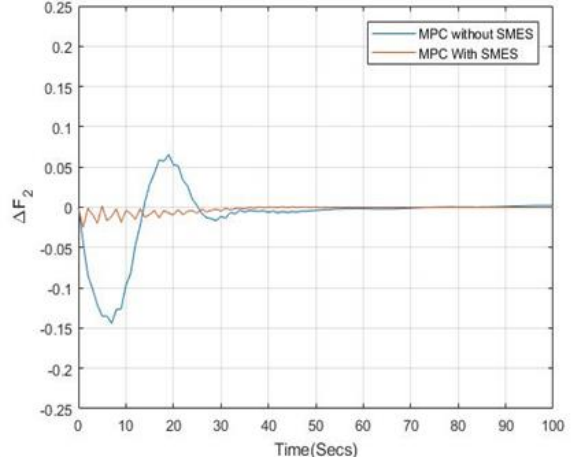

(b)

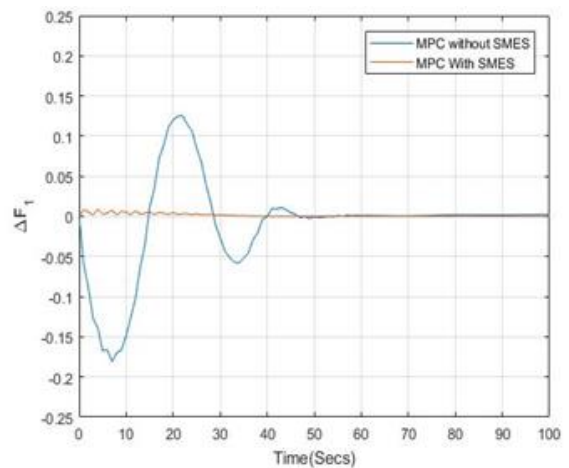

(c)

Figure 4. 1\% Step Load Perturbation Response (a) Thermal Generating Unit (b) Gas Generating Unit (c) Hydro Generating Unit

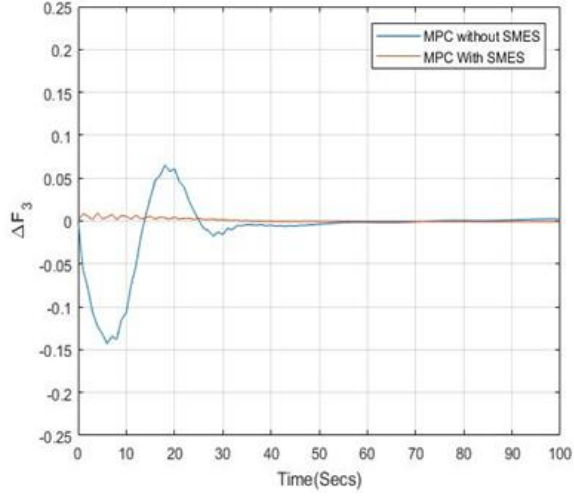

(a)

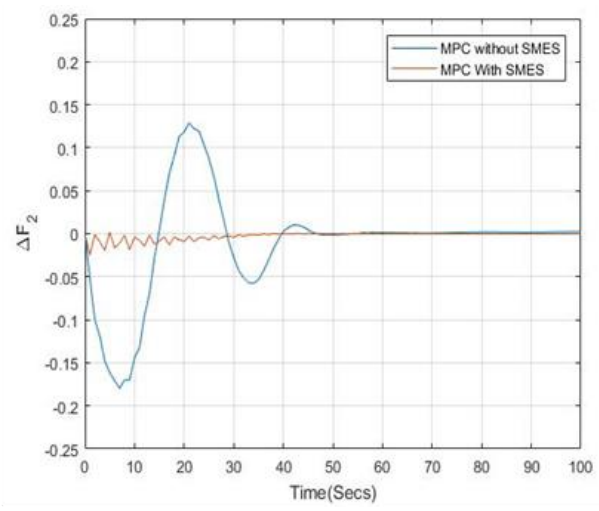

(b)

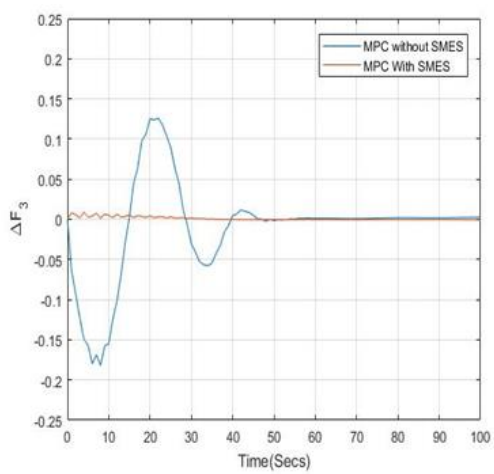

(c)

Figure 5. Step Load Perturbation Response (a) 1.5\% SLP for Thermal Generating Unit (b) $1 \%$ SLP for Gas Generating Unit (c) 1\% SLP for Hydro Generating Unit 
Table 2. MPC with SMES Most Favourable Parameters and the Cost Function

\begin{tabular}{|c|c|c|}
\hline Unit & MPC & SMES \\
\hline Thermal & $\begin{array}{l}T_{s 1}=1, P_{1}=5, M_{1}=1, \\
R_{1}=2, Q_{1}=18\end{array}$ & $\begin{array}{l}\mathrm{K}_{\mathrm{o} 1}=180, \mathrm{~L}_{1}=10, \mathrm{I}_{\mathrm{do} 1}=6, \\
\mathrm{~K}_{\mathrm{id} 1}=3\end{array}$ \\
\hline Gas & $\begin{array}{l}T_{s 2}=0.1, P_{2}=5, M_{2}=2, \\
R_{2}=2, Q_{2}=18\end{array}$ & $\begin{array}{l}\mathrm{K}_{\mathrm{o} 2}=180, \mathrm{~L}_{2}=8, \mathrm{I}_{\mathrm{do} 2}=5 \\
\mathrm{~K}_{\mathrm{id} 2}=1\end{array}$ \\
\hline Hydro & $\begin{array}{l}T_{s 3}=11, P_{3}=5, M_{3}=2 \\
R_{3}=5, Q_{3}=8\end{array}$ & $\begin{array}{l}\mathrm{K}_{\mathrm{o} 3}=55, \mathrm{~L}_{3}=8, \mathrm{I}_{\mathrm{do} 3}=9 \\
\mathrm{~K}_{\mathrm{id} 3}=1\end{array}$ \\
\hline$J_{2}$ & 0.044084 & \\
\hline
\end{tabular}

Table 2 depicts the most favourable parameters of the MPC and SMES for the three area inter-connected power network (thermal, gas, and hydro). $\mathrm{T}_{s i}$ is the sampling time of the controller, $P_{i}$ is the prediction horizon, $M_{i}$ is the control horizon, $R_{i}$ is the control weight, $Q_{i}$ is the output weight error. For the energy compensator (SMES) $\mathrm{K}_{o i}$ is the gain control loop, $\mathrm{L}_{i}$ is the superconducting inductor, $I_{d o i}$ is the inductor current, and $K_{\text {idi }}$ is the gain of the negative feedback loop. $J_{2}$ is the objective function.

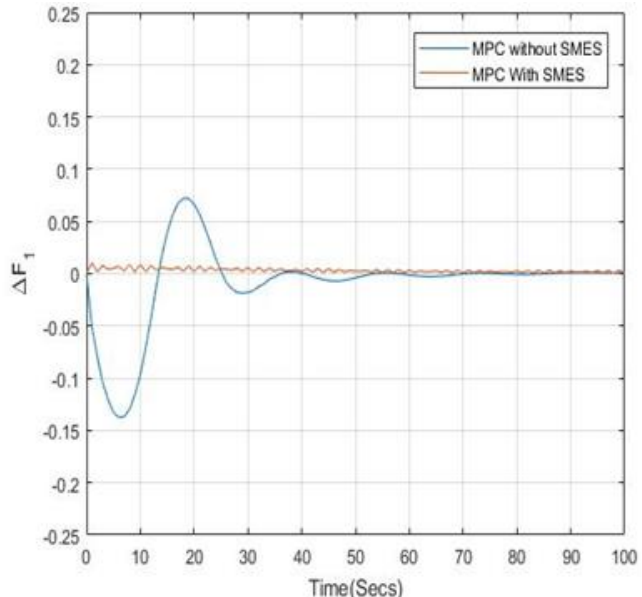

(a)

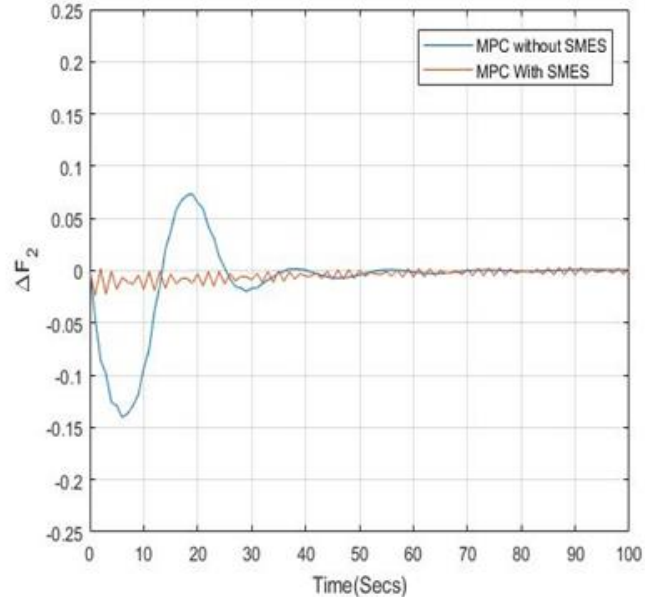

(b)

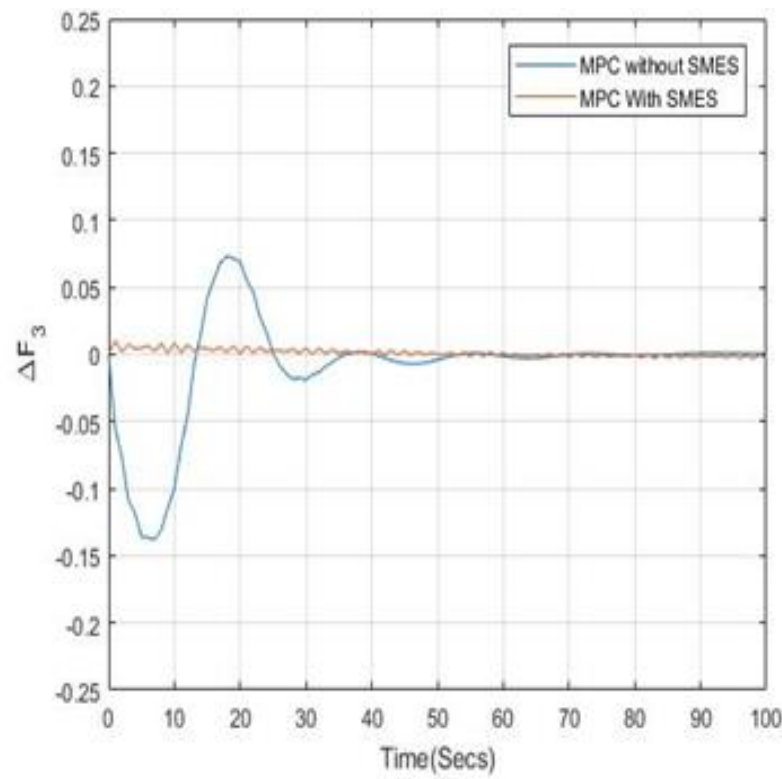

(c)

Figure 6. Increase In 50\% of Tie Line Synchronization Constant (a) Thermal Generating Unit (b) Gas Generating Unit (c) Hydro Generating Unit

KINETIK Vol. 3, No. 4, November 2018: 295-304 


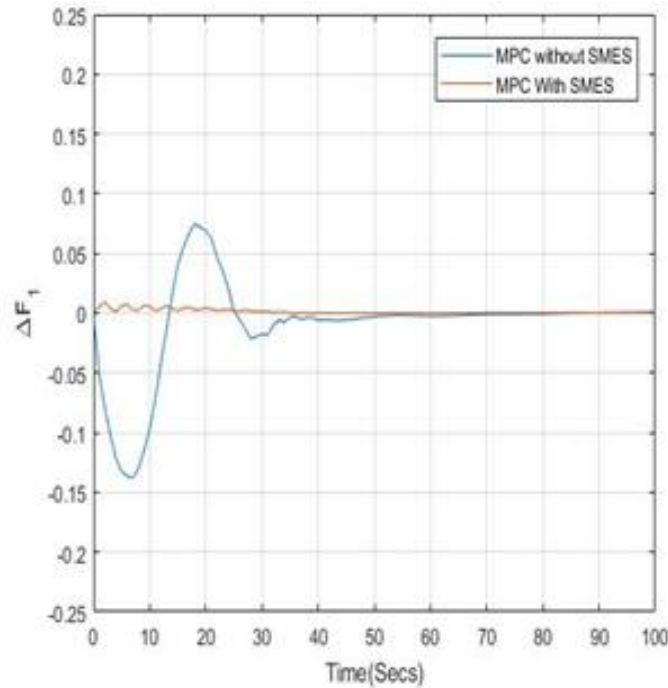

(a)

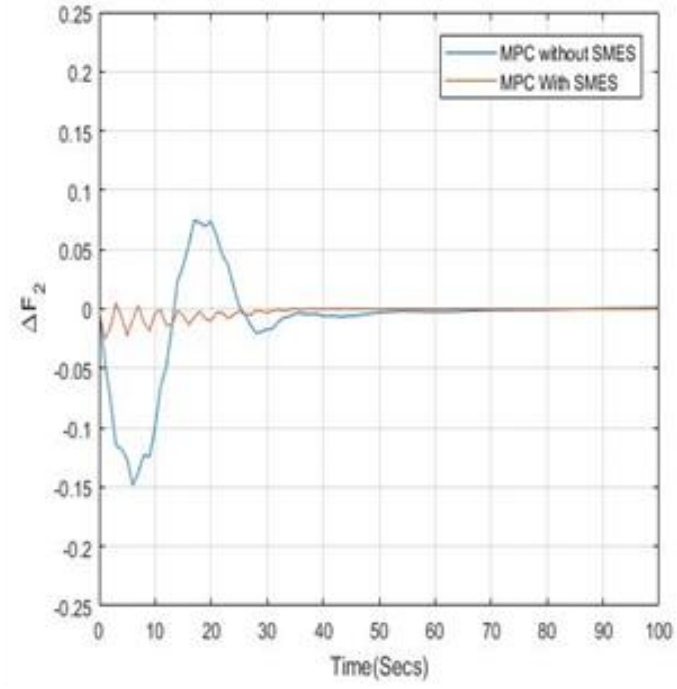

(b)

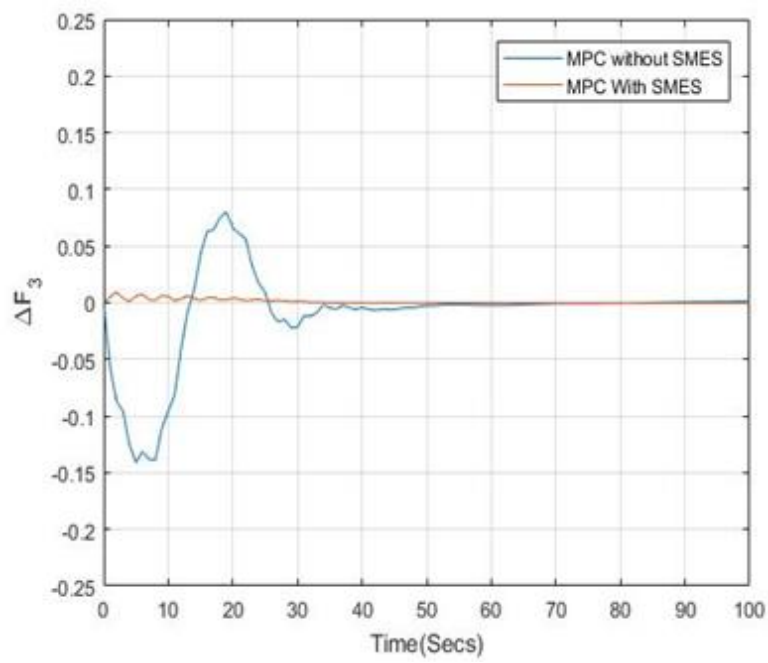

(c)

Figure 7. Decrease in $50 \%$ of Tie Line Synchronization Response (a) Thermal Generating Unit (b) Gas Generating Unit (c) Hydro Generating Unit

\section{Conclusions}

The results displayed shows that the proposed MPC with SMES exhibit a better performance than MPC without SMES as regards settling time, overshoot and undershoot. MPC with SMES takes about 20 seconds to settle after load demand on the generating units, MPC without SMES takes about 40 seconds to settle after load demand on the generating units. The frequency deviation of MPC with SMES is within \pm 0.1 deviation which is better than the frequency deviation of MPC without SMES. The tie line power deviation shown on the simulator takes around 40seconds to be absorbed on each generating unit. The MPC with SMES was able to show efficacy in spite of parametric variation by making the frequency deviation response within \pm 0.1 deviation. The developed simulator allows the flexible variation of the SLP and tie-line synchronization coefficient.

\section{Typical Values for the System Investigated}

\subsection{Thermal Generating Unit}

$\mathrm{T}_{\mathrm{g}}=0.2 \mathrm{~second}$; Boiler data $\left(\mathrm{K}_{1}=0.85, \mathrm{~K}_{2}=0.095, \mathrm{~K}_{3}=0.92, \mathrm{C}_{\mathrm{b}}=200, \mathrm{~T}_{\mathrm{f}}=10, \mathrm{~K}_{\mathrm{ib}}=0.03\right) ; \mathrm{SMES}$ data $\left(T_{d c}=0.026\right) ; \quad K_{r 1}=0.333, T_{r 1}=10$ seconds, $\quad B_{1}=0.425 p . u M W / H z, \quad R_{1}=2.4 \mathrm{~Hz} / p . u M W$, $T_{t 1}=0.3$ second, $K_{p 1}=120, T_{p 1}=20$. 
5.2 Gas Generating Unit

$C_{g}=1, b_{g}=0.05$ second, $X_{C}=0.6$ second, $Y_{C}=1$ second, $T_{C R}=0.01$ second, $T_{F}=0.23$ second, $T_{C D}=0.2$ secon

d , $K_{p 2}=120, T_{p 2}=20$.

\subsection{Hydro Generating Unit}

$\mathrm{T}_{1}=48.7$ seconds, $\mathrm{T}_{2}=0.513$ second, $\mathrm{T}_{3}=10$ seconds, $\mathrm{T}_{\mathrm{w}}=1$ second, $\mathrm{T}_{\mathrm{ij}=}=0.0707 \mathrm{MW} / \mathrm{rad}, \mathrm{aij}_{\mathrm{ij}}=-1$, $\mathrm{K}_{\mathrm{p} 3}=120, \mathrm{~T}_{\mathrm{p} 3}=20$.

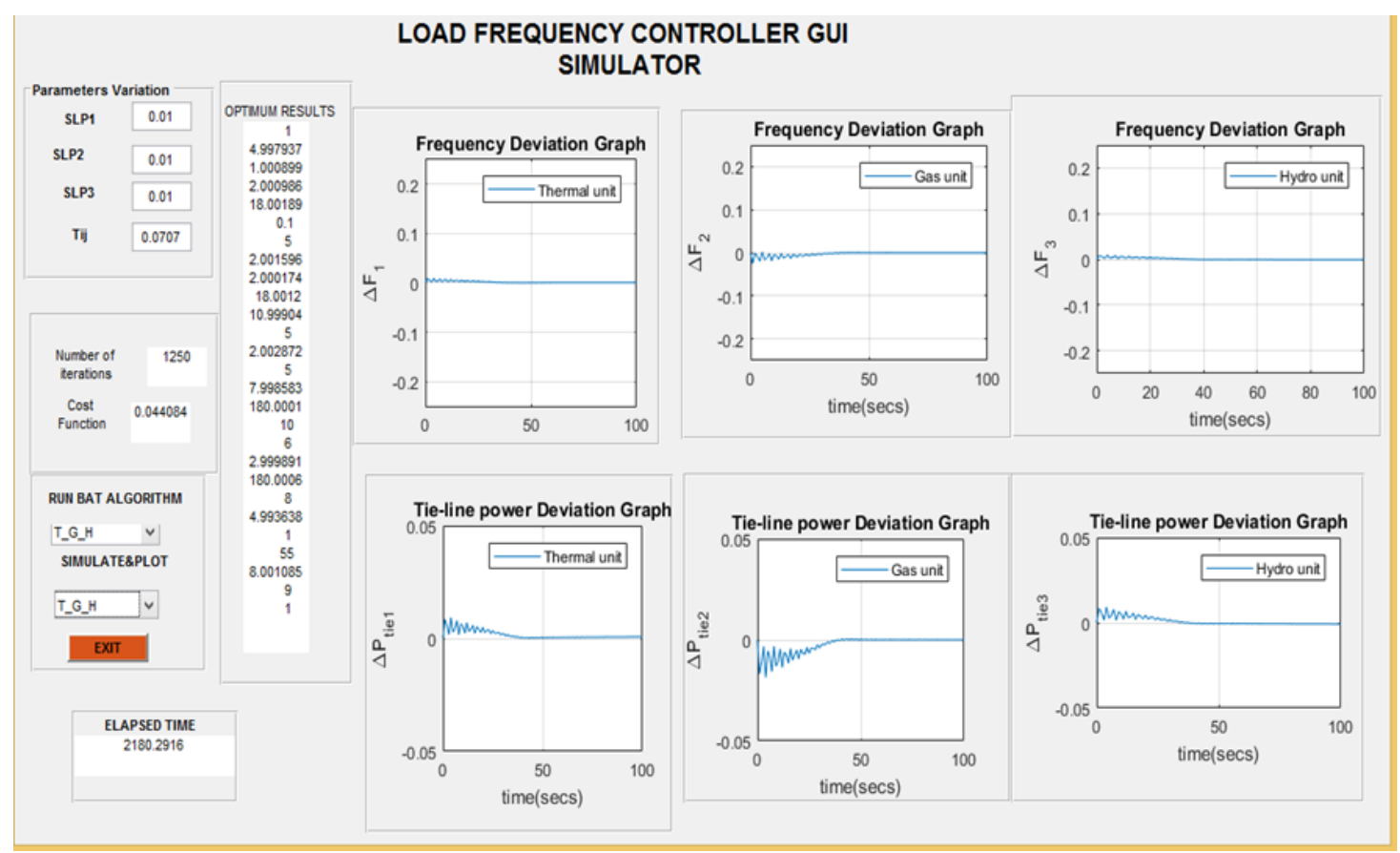

Figure 8. Three Area Power System Simulator

Figure 8 is the developed simulator. The parametric variation section is where the load and tie-line synchronization coefficient can be varied. The optimum results section displays the most favourable parameters of the subordinate controller and the energy compensator. The elapsed time represents the time taken to select the most favourable parameters for controller and energy compensator. The cost function is the value minimized by the ITSE. The frequency responses of each area and tie-line power deviation error are also displayed.

\section{Acknowledgments}

The authors would like to appreciate the effort of the Editor and the Critics for their priceless comments and submissions for refining the quality of the manuscript, the authors are also indebted to the Nigeria Liquefied Natural Gas Limited (NLNG) for their support in equipping the Lab for simulating this work.

\section{Notations}

$J_{1} \quad:$ Cost function of the Model Predictive Controller

$N_{p} \quad$ :Prediction horizon; $r$; set point

$\hat{y} \quad$ :Predicted process output; $\Delta u$ : predicted change in control value

$Q \quad$ :Output error weight matrix

$R \quad$ :Control weight matrix

$J_{2} \quad$ :Area control error cost function

\section{References}

[1] K. Jagatheesan, S. Samanta, A. Choudhury, N. Dey, B. Anand, and A. S. Ashour, "Quantum Inspired Evolutionary Algorithm in Load Frequency Control of Multi-area Interconnected Thermal Power System with Non-linearity," Quantum Computing: An Environment for Intelligent Large Scale Real Application, Pp. 389-417, 2018.

KINETIK Vol. 3, No. 4, November 2018: 295-304 
[2] M. Elsisi, M. Soliman, M. A. S. Aboelela, and W. Mansour, "Improving the Grid Frequency by Optimal Design of Model Predictive Control with Energy Storage Devices," Optimal Control Applications and Methods, No. April 2016, Pp. 1-18, 2017.

[3] B. Mohanty, S. Panda, and P. K. Hota, "Controller Parameters Tuning of Differential Evolution Algorithm and its Application to Load Frequency Control of Multi-Source Power System," International Journal of Electrical Power and Energy Systems, Vol. 54, Pp. 77-85, 2014.

[4] V. Jeyalakshmi and P. Subburaj, "PSO-Scaled Fuzzy Logic to Load Frequency Control In Hydrothermal Power System," Soft Computing, Vol. 20, No. 7, Pp. 2577-2594, 2016.

[5] R. Shankar, S. R. Pradhan, K. Chatterjee, and R. Mandal, "A Comprehensive State of the Art Literature Survey on LFC Mechanism for Power System," Renewable and Sustainable Energy Reviews, Vol. 76, No. February, Pp. 1185-1207, 2017.

[6] M. Elsisi, M. Soliman, M. A. S. Aboelela, and W. Mansour, "Bat Inspired Algorithm Based Optimal Design of Model Predictive Load Frequency Control," International Journal of Electrical Power and Energy Systems, Vol. 83, Pp. 426-433, 2016.

[7] M. Elsisi, M. Soliman, M. A. S. Aboelela, and W. Mansour, "Optimal Design of Model Predictive Control with Superconducting Magnetic Energy Storage for Load Frequency Control of Nonlinear Hydrothermal Power System Using Bat Inspired Algorithm," Journal of Energy Storage, Vol. 12, Pp. 311-318, 2017.

[8] A. Rahman, S. K. Sahu, L. C. Saikia, and P. Dash, "AGC of a Multi-Area Thermal-CCGT System Using Cuckoo Search Optimized Classical Controllers," Pp. 1-6, 2015.

[9] A. Y. Abdelaziz and E. S. Ali, "Cuckoo Search Algorithm Based Load Frequency Controller Design for Nonlinear Interconnected Power System," International Journal of Electrical Power and Energy Systems, Vol. 73, Pp. 632-643, 2015.

[10]H. Shabani, B. Vahidi, and M. Ebrahimpour, "A Robust PID Controller Based on Imperialist Competitive Algorithm for Load-Frequency Control of Power Systems," ISA Transactions, Vol. 52, No. 1, Pp. 88-95, 2013.

[11] Rashmita Gochhhayat, "PSO Based Pi Controller for Load Frequency Control Of Interconnected Power Systems," 2014.

[12]Y. Yoon and Y. Kim, "Charge Scheduling of an Energy Storage System under Time-of-Use Pricing and a Demand Charge," Vol. 2014, 2014.

[13]X. Yang and A. Hossein Gandomi, "Bat Algorithm: A Novel Approach for Global Engineering Optimization," Engineering Computations, vol. 29, No. 5, Pp. 464-483, 2012.

[14] H.-P. Halvorsen, “Model Predictive Control in LabVIEW,” Pp. 0-21, 2011. 
